\title{
Nota Científica \\ Capacidade energética da madeira e da casca de acácia-negra em diferentes espaçamentos
}

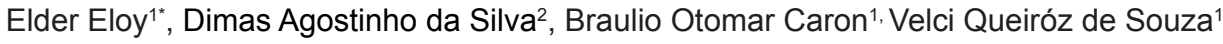 \\ ${ }^{1}$ Universidade Federal de Santa Maria, Linha 7 de Setembro, s/n, BR 386 Km 40, CEP 98400-000, Frederico Westphalen, RS, Brasil \\ 2Universidade Federal do Paraná, Av. Pref. Lothário Meissner, 900, CEP 80210-170, Jardim Botânico, Curitiba, PR, Brasil
}

\author{
"Autor correspondente: \\ eloyelder@yahoo.com.br \\ Termos para indexação: \\ Acacia mearnsii De Wild. \\ Densidade de plantio \\ Recursos dendroenergéticos \\ Index terms: \\ Acacia mearnsii De Wild. \\ Planting density \\ Energy resource wood
}

Histórico do artigo:

Recebido em 29/10/2013

Aprovado em 20/05/2015

Publicado em 30/062015

doi: 10.4336/2015.pfb.35.82.606

\begin{abstract}
Resumo - O trabalho teve por objetivo realizar a descrição dendroenergética da biomassa de madeira e casca de Acacia mearnsii De Wild. distribuída em dois espaçamentos de plantio: 2,0 m x 1,0 m e 3,0 m x 1,5 m, aos 36 meses após o plantio. O experimento foi conduzido no município de Frederico Westphalen, RS. Determinouse a biomassa (BIO), poder calorífico superior, massa específica básica, teor de cinzas, material volátil e carbono fixo e a densidade energética (DE) da madeira e da casca. O menor espaçamento de plantio apresenta maior produção de BIO e DE da madeira e casca por unidade de área.
\end{abstract}

\section{Energy capacity of black wattle wood and bark in different spacing plantations}

\begin{abstract}
The study aimed at the energetic description of wood and bark biomass of Acacia mearnsii De Wild. in two spacing plantations: $2.0 \mathrm{~m} \times 3.0 \mathrm{~m} \times 1.0 \mathrm{~m}$ and $1.5 \mathrm{~m}$, during 36 months after the planting. The experiment was conducted in the municipality of Frederico Westphalen, state of Rio Grande do Sul, Brazil. Biomass (BIO), calorific value, basic density, ash content, volatile matter and fixed carbon content and energy density (ED) of wood and bark were determined. The smallest spacing plantation presented the highest production per unit area of BIO and ED of wood and bark.
\end{abstract}

No campo energético, a madeira é tradicionalmente denominada de lenha e, com esse uso, sempre contribuiu para o desenvolvimento da humanidade, sendo inicialmente empregada para aquecimento e cocção de alimentos. Ao longo dos tempos, foi sendo empregada também em processos para a geração de energia térmica, mecânica e elétrica (Brito, 2007). Em se tratando de materiais combustíveis, como é o caso da madeira, o conhecimento do seu potencial para produção de biomassa e do seu poder calorífico, são fatores importantes para a escolha de uma espécie como fonte energética.

O poder calorífico da madeira consiste na quantidade de energia na forma de calor liberada pela combustão completa de uma unidade de massa do material combustível (Çengel \& Boles, 2006). Ele pode ser obtido por bomba calorimétrica a partir do combustível seco, em que a combustão se efetua a volume constante, no qual a água formada é condensada e o calor resultante é recuperado (Briane \& Doat, 1985). 
Acacia mearnsii De Wild. (Acácia-negra) pertence à família Fabaceae e caracteriza-se por apresentar rápido crescimento, sendo que sua altura pode atingir até $18 \mathrm{~m}$ quando adulta (Freddo, 1997). Cresce em zonas climáticas úmidas e subúmidas, quentes e frias. Essas regiões apresentam temperatura máxima média do mês mais quente entre $22^{\circ} \mathrm{C}$ e $28^{\circ} \mathrm{C}$.

No Brasil, grande parte dos plantios de acácianegra localiza-se na região fisionômica natural do Rio Grande do Sul, denominada de Serra do Sudeste (Escudo Rio-Grandense) e Depressão Central (Dedecek et al., 1998). Apresenta-se como uma espécie de grande importância econômica no extremo sul do país, sendo cultivada em mais de 10 mil pequenas propriedades rurais, exercendo, portanto, importante papel socioeconômico (Oliveira et al., 2006).

Como se sabe, o espaçamento e a idade de corte encontram-se intimamente relacionados, ou seja, plantios com maior densidade populacional normalmente exigem desbastes ou ciclos mais curtos de cortes, pois a competição entre plantas ocorre mais precocemente, antecipando a estagnação do crescimento do povoamento (Eloy et al., 2010). Assim, quando se tem como objetivo a produção madeireira para fins energéticos, normalmente recomendam-se espaçamentos mais adensados, tendo em vista a produção de um maior volume de biomassa por unidade de área em menor espaço de tempo possível.

Dentro desse contexto, esse trabalho teve como objetivo analisar a capacidade energética da madeira e da casca da espécie florestal Acacia mearnsii.

$\mathrm{O}$ trabalho foi realizado em área pertencente ao Laboratório de Agroclimatologia (LAGRO), vinculado à Universidade Federal de Santa Maria (UFSM), Campus do Centro de Educação Superior Norte do Rio Grande do Sul (CESNORS), sob coordenadas geográficas de $27^{\circ} 22^{\prime \prime S} ; 53^{\circ} 25^{\prime \prime} \mathrm{W}$, a $480 \mathrm{~m}$ de altitude, no município de Frederico Westphalen, RS.

A área experimental está distante de Iraí à aproximadamente $30 \mathrm{~km}$, sendo o município tomado como referência para os dados de classificação climática. Segundo a classificação climática de Köppen o clima da região é Cfa. Conforme proposta de Maluf (2000) Iraí possui clima de tipo subtemperado subúmido, sendo a temperatura média anual de $18,8^{\circ} \mathrm{C}$ e temperatura média do mês mais frio de $13,3{ }^{\circ} \mathrm{C}$.

O experimento foi instalado utilizando o delineamento de blocos completos casualizados, em que foi avaliada uma espécie florestal (Acacia mearnsii) e dois espaçamentos de plantio $(2,0 \mathrm{~m} \times 1,0 \mathrm{~m}, \mathrm{e} 3,0 \mathrm{~m} \times 1,5 \mathrm{~m})$ que foram estudados como tratamentos, em três repetições com seis plantas cada.

As avaliações foram realizadas aos 36 meses após o plantio das mudas. Foram selecionadas 36 árvores, que corresponderam a 18 árvores por espaçamento, sendo 6 árvores por repetição, distribuídas em parcelas previamente selecionadas no plantio. Destas amostras, foram retirados cinco discos com, aproximadamente, dois centímetros de espessura, nas seguintes posições no tronco: $0 \%$ (base), 1,30 m (diâmetro à altura do peito - DAP), 25\%, 50\% e 75\% da altura total da árvore (Sanquetta et al., 2004).

Para determinação da biomassa da madeira e da casca utilizou-se o método direto que consiste na derrubada e pesagem dos diferentes compartimentos das árvores (Sanquetta et al., 2004). De cada seção ao longo do tronco, foram retirados discos como amostras para aferição de sua massa úmida e seca em laboratório.

As cunhas de madeira foram submersas em água, onde permaneceram até atingirem a saturação. Para a obtenção da massa específica básica de cada cunha, determinou-se o volume verde e a massa seca em estufa a $103 \pm 2{ }^{\circ} \mathrm{C}$, com circulação e renovação do ar até massa constante, conforme especificado na norma NBR11941 (Associação Brasileira de Normas Técnicas, 2003).

A massa específica básica da madeira e da casca em cada posição relativa do tronco foi determinada pela média dos valores das duas cunhas. Em seguida, calculou-se a massa específica básica ponderada em função do volume total sem casca de cada árvore. Esse cálculo baseia-se na ponderação dos valores de massa específica básica obtida em cada posição relativa, com os volumes sem casca correspondentes entre duas posições sucessivas e com o volume total sem casca da árvore, definido pelo método de Smalian (Finger, 2002).

As amostras de madeira e casca foram moídas em moinho de facas, com peneira de 40 mesh, visando à obtenção de material mais fino e uniforme. A determinação do poder calorífico superior da madeira e casca das árvores foi realizada utilizando bomba calorimétrica digital, modelo C5000 1 Cooling System, IKA Werke, com princípio de funcionamento isoperibólico, de acordo com a norma NBR8633 (Associação Brasileira de Normas Técnicas, 1984).

O poder calorífico superior da madeira e casca em cada posição relativa do tronco foi determinado pela média dos valores das duas cunhas. Em seguida, 
calculou-se o poder calorífico superior ponderado em função do peso total de cada árvore. Esse cálculo baseiase na ponderação dos valores de PCS obtidos em cada posição relativa, dos pesos das biomassas de madeira e casca correspondentes entre duas posições sucessivas com o peso total da árvore.

Para a determinação do teor de material volátil, de cinzas e de carbono fixo, os ensaios foram realizados obedecendo à norma NBR8112 (Associação Brasileira de Normas Técnicas, 1986).

A densidade energética da madeira e da casca foi calculada com base na multiplicação dos valores da massa especifica básica e poder calorífico superior.

Os dados obtidos foram submetidos à análise estatística por meio do Software "Statistical Analysis System" (SAS Institute, 2003), em que se determinou a análise de variância e o teste de Tukey em nível de 5\% de probabilidade de erro.

A análise de variância revelou diferença significativa entre os espaçamentos de plantio para a madeira de $A$. mearnsii, considerando as variáveis massa específica básica, teor de cinzas, produção de biomassa e densidade energética e para a casca, para as variáveis poder calorífico superior, teor de materiais voláteis, teor de carbono fixo, produção de biomassa e densidade energética.

Ao analisar o poder calorífico superior das árvores de Acacia mearnsii, observou-se maiores valores na casca, quando comparado com a madeira. Este resultado corrobora com os resultados de Vale et al. (2002) na caracterização energética da madeira e da casca de 47 espécies, incluído nativas e exóticas, em que, em geral, os valores obtidos para poder calorífico superior da casca mostraram-se superiores àqueles obtidos para a madeira.

Da mesma forma, não foi evidenciada uma variação sistemática crescente ou decrescente em relação ao espaço vital proporcionado pelo espaçamento, ou seja, a madeira possui os maiores valores de poder calorífico (4.577 kcal kg-1) no maior espaçamento de plantio (3,0 m x 1,5 m), Já para a casca, os maiores valores $\left(4.751 \mathrm{kcal} \mathrm{kg}^{-1}\right)$ estão presentes no menor espaçamento $(2,0 \mathrm{~m} \times 1,0 \mathrm{~m})$ (Tabela 1). Esses valores são superiores aos encontrados por Silva et al. (2012) de $4.482 \mathrm{kcal} \mathrm{kg}^{-1}$, para A. mearnsii nas mesmas condições de experimentos.

Tabela 1. Teste de comparação de média para o poder calorífico superior (PCS), massa específica básica (ME), teor de materiais voláteis (MV), teor de cinzas (CZ), teor de carbono fixo (CF), biomassa (Bio) e densidade energética (DE), da madeira e da casca da Acacia mearnsii distribuída nos espaçamentos 2,0 x 1,0 m e 3,0 x 1,5 m, aos 36 meses após o plantio, no município de Frederico Westphalen, RS.

\begin{tabular}{|c|c|c|c|c|c|c|c|}
\hline \multirow{2}{*}{ Espaçamento } & \multirow{2}{*}{$\begin{array}{c}\text { PCS } \\
\left(\mathrm{kcal} \mathrm{kg}^{-1}\right)\end{array}$} & \multirow{2}{*}{$\operatorname{ME}\left(\mathrm{g} \mathrm{cm}^{-3}\right)$} & MV & $\mathrm{CZ}$ & $\mathrm{CF}$ & \multirow{2}{*}{$\begin{array}{c}\text { Bio } \\
(\text { ton ha-1) }\end{array}$} & \multirow{2}{*}{$\begin{array}{c}\mathrm{DE} \\
\left(\text { Gcal m}^{-3}\right)\end{array}$} \\
\hline & & & \multicolumn{3}{|c|}{$(\%)$} & & \\
\hline \multicolumn{8}{|c|}{ Madeira } \\
\hline $2,0 \times 1,0 \mathrm{~m}$ & $4.558 \mathrm{a}$ & $0,471 \mathrm{a}$ & $82,38 \mathrm{a}$ & $0,66 \mathrm{~b}$ & $16,96 \mathrm{a}$ & $45,00 \mathrm{a}$ & $2,147 \mathrm{a}$ \\
\hline $3,0 \times 1,5 \mathrm{~m}$ & $4.577 \mathrm{a}$ & $0,415 \mathrm{~b}$ & $82,23 \mathrm{a}$ & $0,88 \mathrm{a}$ & $16,90 \mathrm{a}$ & $7,29 \mathrm{~b}$ & $1,899 \mathrm{~b}$ \\
\hline \multicolumn{8}{|c|}{ Casca } \\
\hline $2,0 \times 1,0 \mathrm{~m}$ & $4.751 \mathrm{a}$ & $0,372 \mathrm{a}$ & $66,74 \mathrm{~b}$ & $2,80 \mathrm{a}$ & $30,46 \mathrm{a}$ & $14,20 \mathrm{a}$ & $1,767 \mathrm{a}$ \\
\hline $3,0 \times 1,5 \mathrm{~m}$ & $4.641 \mathrm{~b}$ & $0,333 \mathrm{a}$ & $69,95 \mathrm{a}$ & $2,77 \mathrm{a}$ & $27,28 \mathrm{~b}$ & $2,19 \mathrm{~b}$ & $1,512 \mathrm{~b}$ \\
\hline
\end{tabular}

Médias seguidas por letras iguais na mesma coluna não diferem entre si a 5\% de probabilidade de erro conforme o teste de Tukey.

A densidade energética e os teores de materiais voláteis da madeira de Acacia mearnsii foram superiores aos da casca nos dois espaçamentos estudados.

A partir da análise do teste de médias para a biomassa da madeira e casca, aos 36 meses após o plantio (Tabela 1), observou-se uma relação direta da densidade de plantio com a produção da biomassa, ou seja, no tratamento com maior densidade $(2,0 \mathrm{~m} \times 1,0 \mathrm{~m})$ foram observados os maiores valores de biomassa quando comparado com o espaçamento menos adensado (3,0 $\mathrm{m}$ x 1,5 m). Para Oliveira Neto et al. (2003), ocorre maior produção de biomassa por unidade de área nos espaçamentos mais reduzidos, influenciado principalmente pelo maior número de indivíduos. 
Esses resultados corroboram com diferentes autores que desenvolveram trabalhos relacionados à influência da densidade de plantio na produção de povoamentos florestais. Dentre esses, pode-se citar os desenvolvidos por Schneider et al. (2001) e Müller et al. (2005), trabalhando com A. mearnsii e E. grandis, respectivamente. Caron et al. (2015) encontrou diferença na distribuição da biomassa de $A$. mearnsii e de outras de espécies. Esses autores verificaram diferenças entre espécies e para a mesma espécie, em função de fatores como espaçamento de plantio, idade do povoamento e qualidade de sítio.

Foram observados teores de cinzas e carbono fixo, em maior quantidade na casca, quando comparada com a madeira (Tabela 1).

Combustíveis com alto de teor carbono fixo e baixos teores de materiais voláteis tendem a se queimar mais lentamente, implicando em um maior tempo de residência na fornalha para a queima total, em comparação com os combustíveis que tem menores teores de carbono fixo (Brand, 2010).

Ao analisar a massa específica básica das árvores, observou-se que, apesar de não ser verificada diferença significativa, os maiores valores foram para a madeira, podendo-se denotar uma variação sistemática negativa em relação ao espaço vital proporcionado pelo espaçamento, pois os maiores valores estão presente no menor espaçamento $(2,0 \mathrm{~m} \times 1,0 \mathrm{~m}$, Tabela 1$)$, tanto para a massa específica básica da madeira $\left(0,471 \mathrm{~g} \mathrm{~cm}^{-3}\right)$ quanto da casca $\left(0,372 \mathrm{~g} \mathrm{~cm}^{-3}\right)$.

Os resultados de massa específica básica (Tabela 1), estão de acordo com aqueles observados por Vital \& Della Lucia (1987), que não encontraram efeito significativo do espaçamento para essa característica da madeira.

Uma variação sistemática negativa em relação ao espaço vital proporcionado pelos espaçamentos implica em uma maior produção de biomassa e densidade energética da madeira e da casca por unidade de área, no menor espaçamento de plantio, para a espécie estudada (Tabela 1).

\section{Conclusões}

A casca apresenta os maiores valores de poder calorífico superior, teor de cinzas e teor de carbono fixo e a madeira evidenciou os maiores valores de massa específica básica, teor de materiais voláteis, biomassa e densidade energética, independente do tipo de espaçamento.

No que diz respeito ao enfoque energético, apesar de se tratar de um povoamento jovem, Acacia mearnsii apresenta resultados dentro de padrões reconhecidos, sendo possível recomendar o uso dessa espécie para a geração de energia.

\section{Referências}

ASSOCIAÇÃO BRASILEIRA DE NORMAS TÉCNICAS. NBR 8112: análise imediata: material volátil, cinzas, carbono fixo. Rio de Janeiro, 1986. 6 p.

ASSOCIAÇÃO BRASILEIRA DE NORMAS TÉCNICAS. NBR 8633: carvão vegetal: determinação do poder calorífico. Rio de Janeiro, 1984. 13 p.

ASSOCIAÇÃO BRASILEIRA DE NORMAS TÉCNICAS. NBR11941: madeira: determinação da densidade básica. Rio de Janeiro, 2003. 6 p.

BRAND, M. A. Energia de biomassa florestal. Rio de Janeiro: Interciência, 2010.131 p.

BRIANE, D.; DOAT, J. Guide technique de la carbonisation: la fabrication du charbon de bois. Aix-en-Provence: ÉDISUD, 1985.

BRITO, J. B. O uso energético da madeira. Piracicaba: ESALQ/ USP, 2007. p. 185-193. (Estudos Avançados, 21).

CARON, B. O.; ELOY, E.; SOUZA, V. Q.; SCHMIDT, D.; BALBINOT, R.; BEHLING, A. MONTEIRO, G. C. Quantificação da Biomassa florestal em plantios de curta rotação com diferentes espaçamentos. Comunicata Scientiae, v. 6, n. 1, p. 106-112, 2015.

ÇENGEL, Y. A.; BOLES, M. A. Termodinâmica. 5. ed. Bogotá: Mc Graw-Hill, 2006. 740 p.

DEDECEK, R. A.; RACHWAL, M. F. G.; CURCIO, G. R.; SIMON, A. A. Sistemas de preparación del suelo para plantación de Acacia mearnsii en dos lugares y su efecto en la productividad y en la erosión hídrica. In: CONGRESO LATINOAMERICANO IUFRO, 1., 1998, Valdivia, Chile. EI manejo sustentable de los recursos forestales, desafio del siglo XXI: actas. Valdivia, Chile: CONAF: IUFRO, $1998.9 \mathrm{p}$.

ELOY, E.; CARON, B. O.; SOUZA, V. Q.; TREVISAN, R.; BEHLING, A.; BAMBERG, R.; VIAN, A. L.; BUSANELLO, C. Espécies florestais em plantios de curta rotação para biomassa. Revista da Madeira, Curitiba, n. 21, p. 50-53, 2010.

FINGER, C. A. G. Fundamentos de biometria florestal. Santa Maria, RS: UFSM/CEPEF/FATEC, 2002. 269 p.

FREDDO, A. Elementos minerais em madeiras de eucaliptos e acácia-negra e sua influência na indústria de celulose kraft branqueada. 1997. 69 f. Dissertação (Mestrado em Engenharia Florestal) - Universidade Federal de Santa Maria, Santa Maria, RS.

MALUF, J. R. T. Nova classificação climática do Estado do Rio Grande do Sul. Revista Brasileira de Agrometeorologia, Santa Maria, RS, n. 8, 141-150, 2000. 
MÜlleR, M. D.; COUTO, L.; LEITE, H. G.; BRITO, J. O. Avaliação de um clone de eucalipto estabelecido em diferentes densidades de plantio para produção de biomassa e energia. Biomassa \& Energia, Viçosa, MG, v. 2, n. 3, p. 177-186, 2005.

OLIVEIRA NETO, S. N.; REIS, G. G. A.; REIS, M. G. F.; NEVES, J. C. L. Produção e distribuição de biomassa em Eucalyptus camaldulensis Dehn. em resposta à adubação e ao espaçamento. Revista Árvore, Viçosa, MG, v. 27, n. 1, p. 15- 23, 2003. DOI: 10.1590/S0100-67622003000100003

OliveirA, L. S.; COSTA, E. C. C.; CANTARELli, E. B.; PERRANDO, E. R.; PACHECO, D. D. P. Ocorrência de Phaops thunbergi (Coleoptera: Curculionidae) em Acacia mearnsii De Wild. Ciência Rural, Santa Maria, RS, v. 36, n. 3, p. 971-972. 2006. DOI: 10.1590/S0103-84782006000300038

SANQUETA, C. R.; BALBINOT, R.; ZILIOTTO, M. A. B. (Ed.) Fixação de carbono: atualidades, projetos e pesquisas. Curitiba: UFPR, 2004. 205 p.
SAS INSTITUTE. Getting started with the SAS Learning Edition. Cary, 2003. 200 p.

SCHNEIDER, P. R.; FLEIG, F. D.; FINGER, C. A. G.; SPATHELF, P. Produção de madeira e casca verde por índice de sítio e espaçamento inicial de acácia-negra (Acacia mearnsii De Wild.). Ciência Florestal, Santa Maria, RS, v. 11, n. 1, p.151-165, 2001.

SILVA, D. A.; CARON, B. O.; BEHLING, A.; SOUZA, V. Q.; ELOY, E. Ponto de amostragem ao longo do fuste para estimativa do poder calorífico da madeira. Ciência Rural, Santa Maria, RS, v. 42, n. 9, p. 1588-1595, 2012. DOI: 10.1590/S0103-84782012000900012

VALE, A. T.; BRASIL, M. A. M.; LEÃO, A. L. Qualificação e caracterização energética da madeira e casca de espécies do cerrado. Ciência Florestal, RS, v. 12, n. 1, p. 71-80, 2002.

VITAL, B. R.; DELLA LUCIA, R. M. Efeito do espaçamento na produção em peso e na qualidade da madeira de Eucalyptus grandis e Eucalyptus saligna aos 52 meses de idade. Revista Árvore, Viçosa, MG, v. 11, n. 2, p. 132-145, 1987. 
